\title{
Experimental study on diffusive solid combustion behavior during transition from normal- to reduced-gravity
}

\author{
L.H. Hu ${ }^{\text {a,* }}$, M.A. Delichatsios ${ }^{\text {b }}$, J. Li ${ }^{\text {a }}$, X.L. Zhang ${ }^{\text {a }}$, S.F. Wang ${ }^{\text {c,* }}$, R. Huo ${ }^{\text {a }}$ \\ a State Key Laboratory of Fire Science, University of Science and Technology of China, Hefei, Anhui 230026, China \\ ${ }^{\mathrm{b}}$ FireSERT, School of Built Environment and Built Environment Research Institute, University of Ulster, Newtownabbey BT38 8GQ United Kingdom \\ ${ }^{\mathrm{c}}$ Key Laboratory of Microgravity, Institute of Mechanics, Chinese Academy of Sciences, Beijing 100080, China
}

\section{A R T I C L E I N F O}

\section{Article history:}

Received 8 March 2011

Received in revised form 24 October 2011

Accepted 10 November 2011

Available online 30 December 2011

\section{Keywords:}

Reduced-gravity

Combustion of solid particles

Transition from normal to reduced gravity Luminance

\begin{abstract}
A B S T R A C T
Experiments are carried out in a simplified drop system, which can provide a $2.3 \mathrm{~s} 10^{-2}$ g reduced gravity period, to investigate the transition of solid material combustion behavior from normal- to reduced-gravity. A CCD camera records the diffusion flames produced by a solid fuel, Methenamine $\left(\mathrm{C}_{6} \mathrm{H}_{12} \mathrm{~N}_{4}\right)$, which easily sublimes and decomposes to flammable $\mathrm{CH}_{4}$ and $\mathrm{H}_{2}$. The temperature distribution within the flame is analyzed by a monochromatic line of sight CCD measurement calibrated by a thermocouple measurement. It is revealed that during the transition period from normal- to reduced-gravity, the change of the flame shape, from tall and thin (pear like) to spherical, is faster than that of the luminance which represents the radiation intensity, indicating a relatively shorter adjustment time scale of dynamical gas flow buoyancy than that of the heat transfer when subjected to such a sudden change of gravity condition. It is also found that owing to the change of the flow affecting the oxygen and heat supply, the luminance of the flame as well as the burning rate, which was deduced based on projected area of the solid fuel according to $\mathrm{d}^{2}$-law, first decreases followed by an increment near the end of the drop where the gravity level slightly increases. The flame temperature gradually decreases, as the flame suddenly goes into reduced-gravity. Interpretation based on analysis of heat transfer balance and pyrolysis rate as well as the experimental results both indicate that the transitional effect is less pronounced for a smaller fuel particle than for a larger one, where buoyancy is stronger under normal-gravity whereas the flame has a larger standoff distance with increasing importance of the radiation losses from the fuel particle surface under reduced-gravity. The present work is relevant in assessing fire hazards of solid material during space travel as gravity levels change.
\end{abstract}

(c) 2011 Elsevier Ltd. All rights reserved.

\section{Introduction}

Combustion behavior and flame characteristics under microgravity conditions have attracted extensive research interest [118 ]. Under micro-gravity conditions, the buoyancy force owing to gravitational acceleration disappears. This makes the combustion, the flame shape and structure to be different from those under a normal-gravity condition. Experiments under micro-gravity conditions also provide a way to investigate diffusion and electrostatic effects, which are much smaller and cannot be distinguished under normal-gravity conditions. Importantly, the fast development of space technology in recent years also calls for scientists to understand the combustion behaviors of solid combustible and its flames from normal to micro-gravity conditions concerning the fire safety in spacecraft.

There are already several experimental works in micro-gravity combustion of fuel droplets (e.g. [1-10]), gases (e.g. [11-13]) and

\footnotetext{
* Corresponding authors. Tel.: +86 551 3606446; fax: +86 5513601669.

E-mail addresses: hlh@ustc.edu.cn (L.H. Hu), sfwang@imech.ac.cn (S.F. Wang).
}

even solid combustibles [14-20]. The burning behavior of fuel droplets in microgravity has been investigated extensively for example by Wang [1], Okai [2], Yang [3], Shaw [4,5] and Manzello $[6,7]$ for free fuel droplets or near a wall. Yozgatligil [8] has revealed the sooting behavior of ethanol droplet combustion under micro-gravity conditions through the 2.2-s drop tower at NASA Glenn Research Center. Ogami [10] and Takahashi [11] have investigated the droplet combustion and flame extinguishment behavior under different flow conditions. For solid combustible, Yang [14] has carried out experiments in NASA DC-9 and the KC-135 Reduced Gravity Aircraft to investigate the burning behavior of thermoplastic spheres. Dreizin [15] revealed the flame evolution characteristics of aluminum particles under microgravity condition. Nakamura [16], Bhattacharjee [17] and Altenkirch [18] investigated the ignition and flame spread and extinction over solid materials under microgravity environment.

However, there is another special gravity scenario, i.e. transition of gravity from normal to reduced, for example when a spacecraft enters into an orbits after launch. Drop tower experiments are well suited in the investigation of combustion behavior regarding the 


\section{Nomenclature}

$\begin{array}{ll}c_{p} & \text { specific heat at constant pressure }\left(\mathrm{J} \mathrm{kg}^{-1} \mathrm{~K}^{-1}\right) \\ D & \text { diameter of the solid fuel particle }(\mathrm{m}) \\ E & \text { radiation energy } \\ G r & \text { Grashof number } \\ h & \text { convective heat transfer coefficient }\left(\mathrm{W} \mathrm{m}^{-2} \mathrm{~K}^{-1}\right) \\ I & \text { radiation intensity } \\ k & \text { thermal conductivity }\left(\mathrm{W} \mathrm{m}^{-1} \mathrm{~K}^{-1}\right) \\ \dot{m}^{\prime \prime} & \text { mass flux }\left(\mathrm{kg} \mathrm{s}^{-1} \mathrm{~m}^{-2}\right) \\ \mathrm{Nu} & \text { Nusselt number } \\ \mathrm{Pr} & \text { Prandtl number } \\ \dot{q}^{\prime \prime} & \text { heat loss flux conducted into the particle }\left(\mathrm{kW} \mathrm{m}^{-2}\right) \\ r & \text { radius (m) } \\ S & \text { oxidizer-to-fuel stoichiometric ratio } \\ T & \text { temperature }(\mathrm{K})\end{array}$

$T_{\infty} \quad$ ambient temperature (K)

Greek symbols

$\lambda \quad$ spectrum wavelength $(\mathrm{nm})$

$\varepsilon \quad$ emissivity

$\sigma \quad$ Stefan-Boltzmann constant

$\Delta H_{f g} \quad$ latent heat of gasification per unit fuel mass $(\mathrm{J} / \mathrm{kg})$

$\Delta H_{c} \quad$ heat of combustion per unit fuel mass $(\mathrm{J} / \mathrm{kg})$

Subscripts

$f \quad$ flame

g gas

$s \quad$ solid transition from normal- to reduced-gravity conditions and vice versa. As the experimental capsule drops, it provides a reducedgravity environment before or after the ignition of the sample because the combustible materials might also be ignited before the drop. In such a case, the flame initially develops in the normalgravity condition and suddenly transits into the reduced-gravity condition. We note that for such a free drop in air, the air drag force will cause a slight increase of the gravitational level at the late period of the drop. Because it is well known that the combustion and flame behavior is different under these two gravity conditions, how the flame develops during such a special transitional phase needs to be investigated. Studies on such a transient process are limited. Law [13] and Tien [19] had observed and studied the transient combustion behavior during a change of the gravity level from normal- to reduced-gravity. Gaseous fuel from a porous burner and PMMA, which melts as it burns, were used as the fuel in Law [13] and Tien's [19] experiments respectively.

In this paper, a special solid fuel is used, which does not melt but sublimates to $\mathrm{CH}_{4}, \mathrm{H}_{2}$ and $\mathrm{N}_{2}$ giving out flame with little soot. Experiments described in the next section were carried out in a $2.3 \mathrm{~s}$ drop facility, to investigate the combustion behavior, including flame shape, luminance, burning rate and temperature, during the transition from normal- to reduced-gravity conditions. As known that the flame shape is dominated by the flow buoyancy, while the luminance, burning rate and temperature is dominated by the heat transfer process. Subsequently, how these parameters behavior transiently subjected to such a change of gravity condition are presented followed by analysis of the physics based on heat transfer and interpretation. The last section presents the main findings of this work.

\section{Experimental setup and procedure}

A simplified drop facility has been especially designed and built to carry out the experiments under simulated reduced-gravity condition. As shown in Fig. 1, the combustion capsule is installed at the top of an experimental building (USTC-PolyU Atrium), which is $27 \mathrm{~m}$ high above the floor level. The capsule is cylindrical with a warhead-shape bottom. The diameter and the height of the cylindrical capsule both are $0.5 \mathrm{~m}$. A protection chamber filled with tyres and equipped with a rope net is positioned directly below the capsule. This chamber is cubic with dimensions of $1.5 \mathrm{~m}$ and opened at the top. The capsule is hoisted with an electromagnet device. When the electricity is shut off, the capsule drops. The gravitational acceleration level in the capsule is recorded by a gravitational acceleration sensor. This simplified drop facility can provide a reduced-gravity period of about $2.3 \mathrm{~s}$ Fig. 2 .
A wooden experimental platform is installed at the inner bottom inside the capsule as Fig. 2 shows. The video record system and the combustion system are installed on the platform. A digital video CCD camera, positioned within the video base, which is filled with foam and sponge, is facing the fuel ball to record the development of the flame. A wireless webcam is also positioned at the platform, so that the burning condition can be monitored remotely. The video CCD camera resolution is $1280 \times 720$ pixels with framing rate of 30 frames per second.

Although there are some experimental observations reported regarding spherical flame stability under reduced gravity, the combustibles mainly used were gaseous fuel supplied by a porous burner, liquid droplets or PMMA particles [12,14,17-19]. In this paper, different from previous work, solid Methenamine $\left(\mathrm{C}_{6} \mathrm{H}_{12} \mathrm{~N}_{4}\right)$, which easily sublimates and decomposes to $\mathrm{CH}_{4}, \mathrm{H}_{2}$ and $\mathrm{N}_{2}$ at about $263{ }^{\circ} \mathrm{C}$, is selected as the fuel. As a versatile reagent in organic synthesis, Methenamine is used for processes in rubber and textile adhesives, in paints and lacquers and in the photographic industry. It is also applied as a corrosion inhibitor or a protein modifier. In addition, it produces flames with little soot. Methenamine burns without smoke maintains a steady flame, sublimates keeping its original shape, and leaves no ash. In particular, it can be easily ignited by a spark igniter. A small hole (diameter less than $0.5 \mathrm{~mm}$ ) drilled in the center of the particle was used to support it on a nickel rod on the stand as shown in Fig. 2.

A relay with voltage of $12 \mathrm{~V}$ controlled by wireless remote device is connected to a heating wire to generate enough heat to ignite the fuel ball. Three ball diameters were examined, $5 \mathrm{~mm}$, $8 \mathrm{~mm}$ and $10 \mathrm{~mm}$. Before each test, the ambient wind is monitored by hot-wire anemometer to ensure that there is no wind during the dropping period. The fuel ball is ignited under normal-gravity condition before drop starts. The burning conditions are then monitored through the wireless webcam and recorded by the CCD camera. Because the flame oscillates in normal gravity just after ignition, the experimental capsule is dropped once a stable flame is established just about $10 \mathrm{~s}$ after ignition. The burning of the fuel ball is then occurs under a reduced-gravity environment. Each experiment is repeated at least three times.

\section{Results and discussion}

\subsection{Luminance}

The gravitational acceleration drops to a steady level of about $0.01 \mathrm{~g}$ in $0.25 \mathrm{~s}$ after the drop starts as shown in Fig. 3. It also shows that at $1.5 \mathrm{~s}$ after drop, the gravitational level begins to gradually 


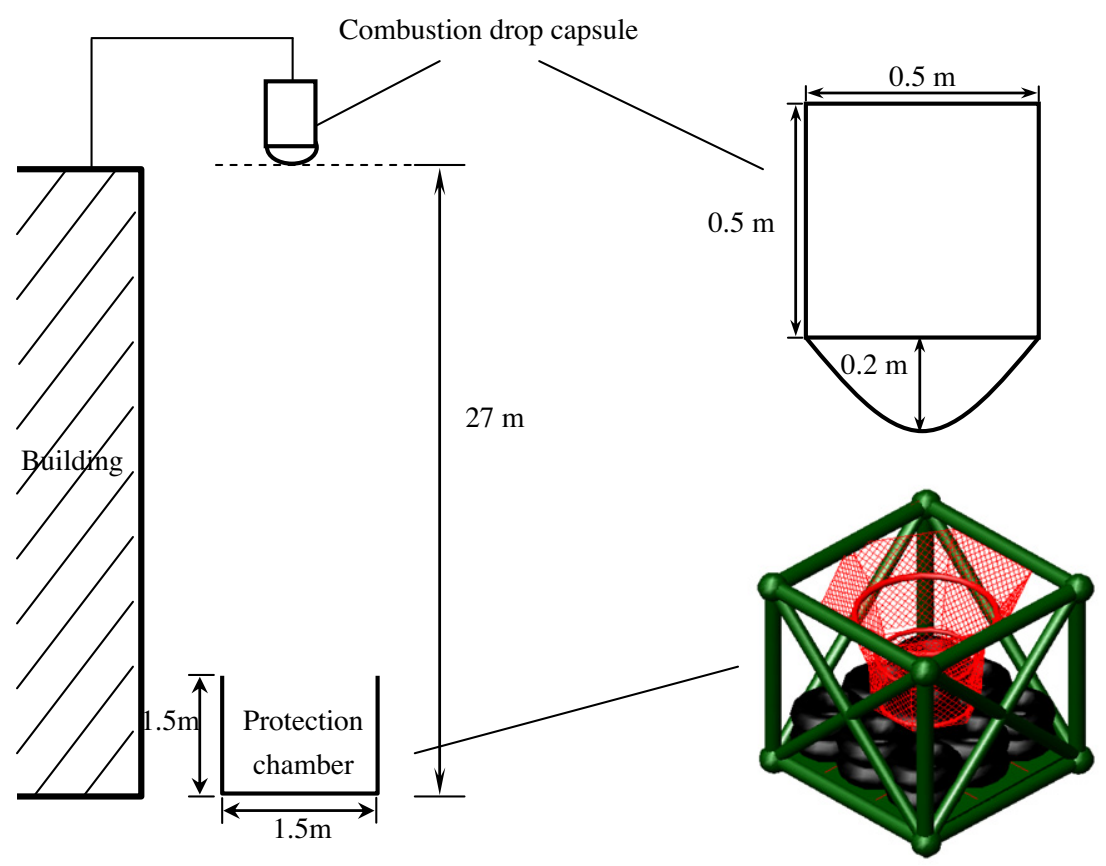

Fig. 1. Schematic of the drop system.

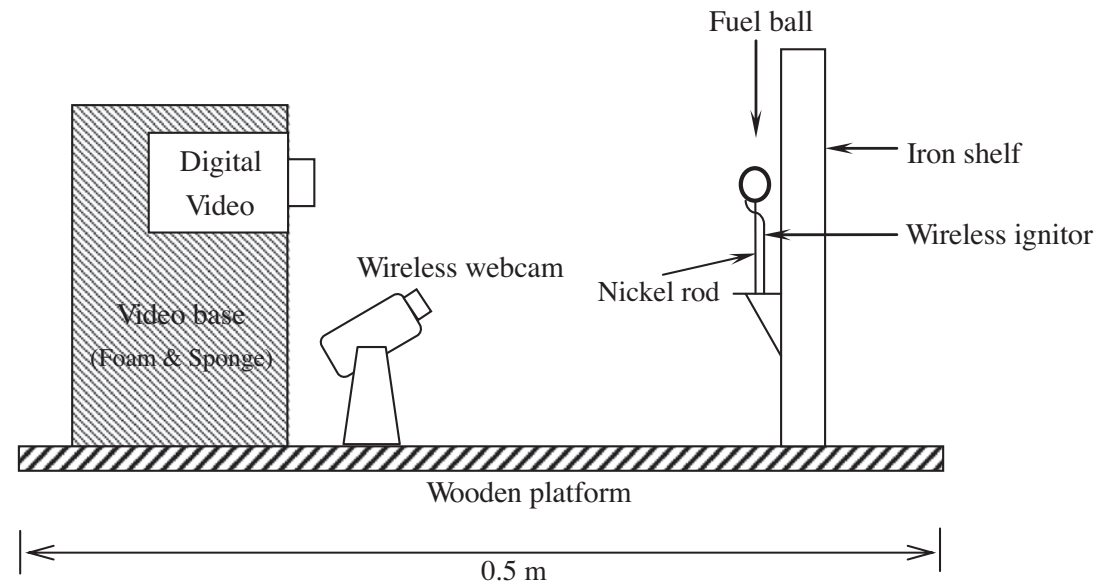

Fig. 2. Layout of the experimental platform located inside the capsule shown in Fig. 1.

increase and finally to about $0.03 \mathrm{~g}$ at the end of the drop owing to deceleration induced by air drag.

The development of the flame is imaged in Fig. 4 at intervals of $1 / 30 \mathrm{~s}$. The flames under normal gravity shown in Fig. 4(a) are relatively tall upwards owing to buoyancy. When the particle enters reduced gravity in Fig. 4(b), the flame is firstly stretched as the upper part of it breaks away from the particle. After about 3 time frames, the flame changes into a nearly spherical shape since burning occurs now at reduced-gravity conditions. These photos corroborated by Figs. 5 and 6 also show that there is a significant change of the flame luminance. Under normal-gravity the flame luminance (see Fig. 5 and 6 ) and burning rate (see Figs. 7 and 8 in terms of projected area of the fuel particle versus time, based on $\mathrm{d}^{2}$-law) are more intense than at reduced-gravity. The particle projected area in Fig. 8 was determined as shown in Fig. 7 by the back-lit method with image processing based on the Canny edge detection method [20]. Specifically, Fig. 5 indicates that the luminance of the larger particles decreases much faster to the microgravity level. Moreover, Fig. 6 shows that the flame size, representing the response to the transition of the gases, also adjusts much faster than the luminance. Finally near the end of the drop, the burning rate and luminance increase a little (5-8) because gravity increases to $0.03 \mathrm{~g}$ as Fig. 3 shows. The experiments were repeated for each case three times always exhibiting nearly the same transitional behavior of the burning and the luminance.

These interesting transition phenomena can be explained by change of the oxygen diffusion and heat supply mechanisms during the particle burning. Under normal-gravity condition, fresh air is entrained into the flame region by buoyancy to react with the gaseous fuel released from the solid fuel surface as the particle pyrolyses from heat received by the flames. But under reducedgravity, the oxygen into the reaction zone and the heat from the flames for pyrolysis are supplied only by diffusion at a rate considerably reduced compared to normal gravity burning. Another important effect affecting the energy balance on the particle surface originates from the heat losses from the surface which consist 


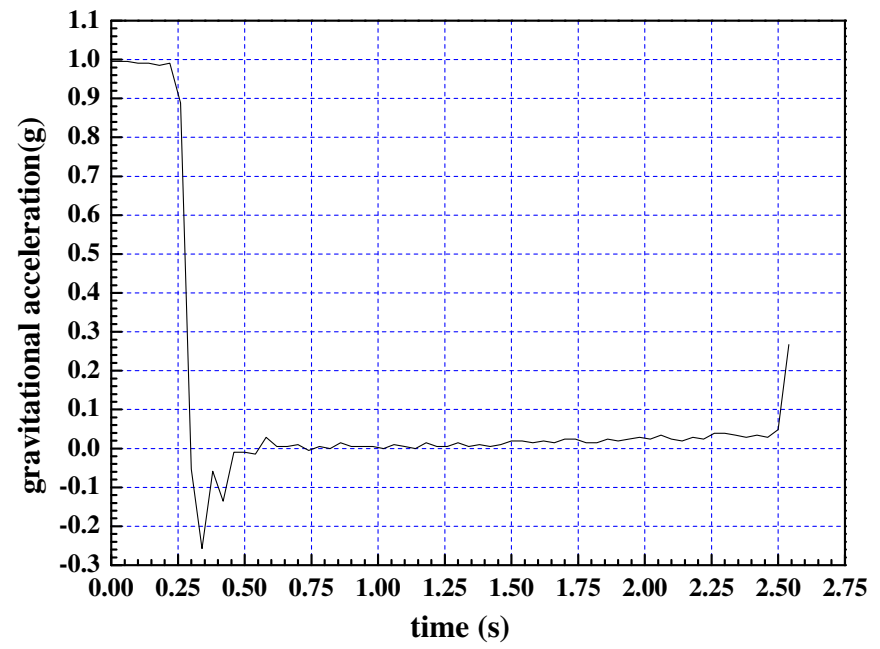

Fig. 3. Gravitational acceleration level during the drop showing that the gravitational acceleration slightly increases near the end of the drop.

of heat losses by conduction into the solid and more importantly, from reradiation from the surface [21-23]).

When suddenly goes into a reduced-gravity condition, the oxygen supply rate drops significantly and swiftly. However, the pyrolysis rate at the solid fuel particle surface is still high as the temperature there is also high at this moment. The sublimated gases, which is $\mathrm{CH}_{4}, \mathrm{H}_{2}$ and $\mathrm{N}_{2}$, accumulates around the solid fuel ball, playing an important role in blockage of radiation from the flame surface to the solid fuel surface. The standoff distance between the flame surface and the solid fuel surface also increased remarkably. The discrepancy between the dynamic response of the flame height and that of the luminance subjected to a sudden

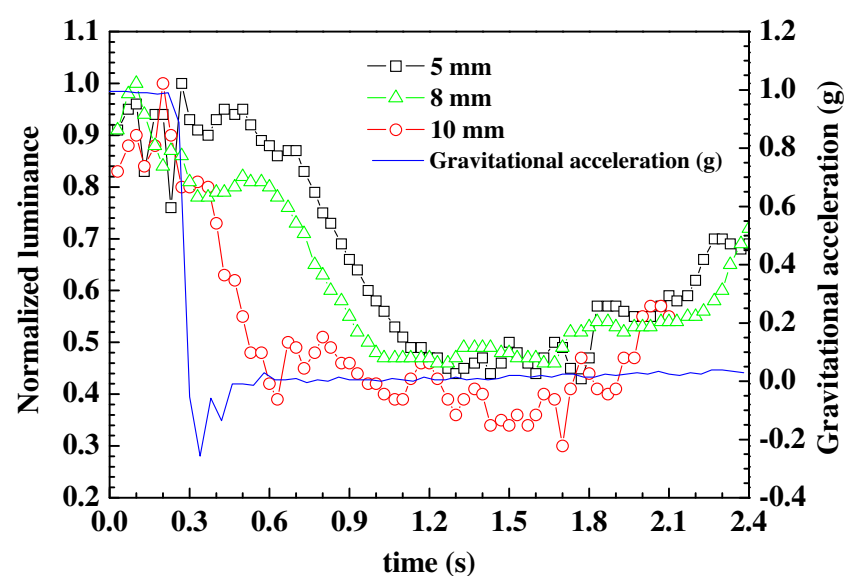

Fig. 5. Variation of normalized luminance during transition from normal- to reduced-gravity condition for fuel balls with different diameters.

change of gravity condition indicates the relatively shorter adjustment time scale of such buoyant gas flow than that of the heat transfer and pyrolysis. It was also found [24] by microgravity experiments that the buoyancy had a remarkable effect on the flow heat transfer mechanism. It follows that the burning rate can be much lower under reduced- than under normal-gravity. To clearly demonstrate and explain the different observed phenomena (decrease of luminance, decrease of burning rate, adjustment of flame size, Figs. 4-8), we present the mass pyrolysis rate for a spherical particle, in considering the energy balance for the solid-gas phase interface surface. The heat transfer from the surrounding hot gas to the solid fuel surface is mainly by conduction, in considering that the radiation part is relative much smaller [19] due to the blockage effect. And the heat loss term includes that in-depth conduction

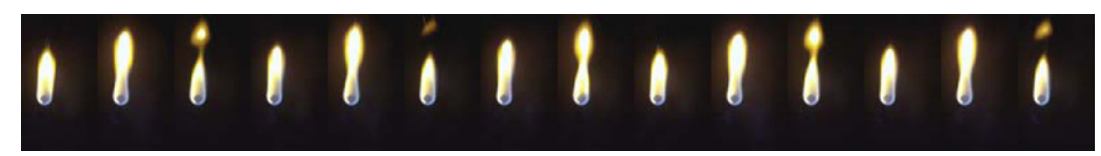

(a) Normal gravity-before drop

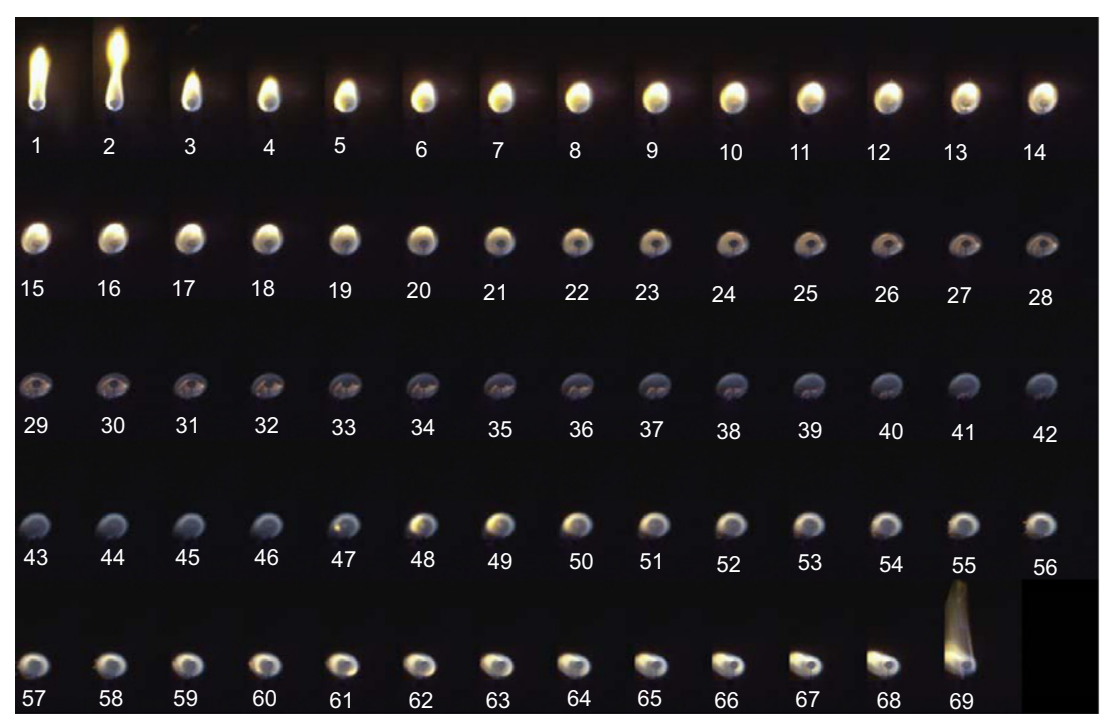

(b) Reduced gravity-right after drop

Fig. 4. Images of the flame transition from normal- to reduced-gravity condition ( $5 \mathrm{~mm}$ fuel ball). 


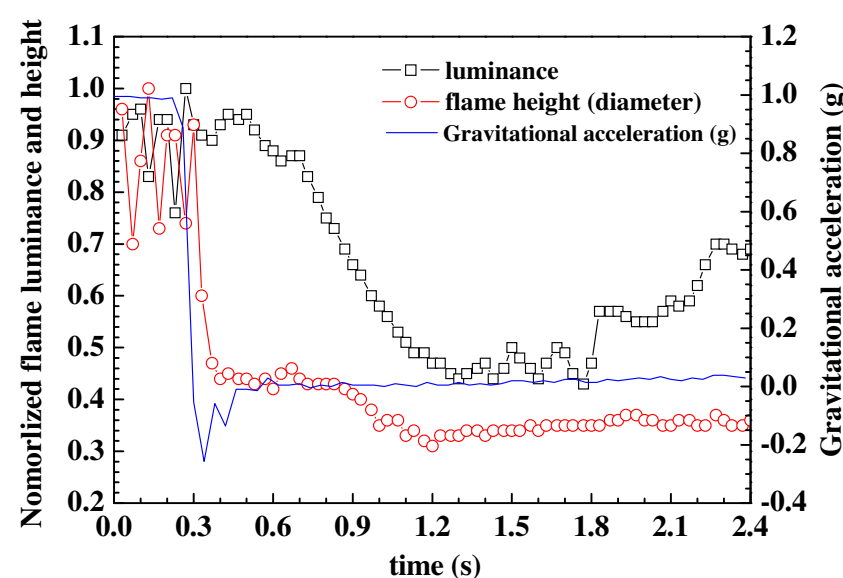

Fig. 6. Transition of flame height (diameter) and luminance along with transition from normal- to reduced-gravity condition ( $5 \mathrm{~mm}$ ball).

into the particle and especially the re-radiation losses from the solid fuel surface.

$\left.k_{g} \frac{\partial T}{\partial r}\right|_{g}=\left.k_{s} \frac{\partial T}{\partial r}\right|_{s}+\dot{m}^{\prime \prime} \Delta H_{f g}+q_{r a d, s}$

So, the net heat supply to the fuel particle is

$\dot{q}_{\text {net }}=4 \pi r_{s}^{2}\left[k_{g}\left(T_{f}-T_{s}\right) /\left(r_{f}-r_{s}\right)-\sigma\left(T_{s}^{4}-T_{\infty}^{4}\right)-\left.k_{s} \frac{\partial T}{\partial r}\right|_{s}\right]$

When entering into the microgravity condition, the gas temperature $T_{f}$ decreases and the standoff distance $\left(r_{f}-r_{s}\right)$ increases, while the in-depth conduction was shown [19] to change little. These both lead to the heat transfer to the solid fuel surface decrease and thus its temperature as well as the burning rate should decreases. For large particle, the change in heat flux after transition is more remarkable, and even will lead to extinction when $\dot{q}_{\text {net }}<0$.

The mass pyrolysis rate can be further expressed as:

$\dot{m}^{\prime \prime}=\frac{k_{g} N u}{c_{p g} D_{s}} \ln \left(1+B_{m}\right)$

where $\quad B_{m}=\frac{\Delta H_{c} / S+c_{p g}\left(T_{\infty}-T_{s}\right)}{q_{\text {Loss }}+\Delta H_{f g}}$

is a modified $B_{m}$ number to account for conduction into the solid and re-radiation surface losses [21].
Here the Nusselt number is determined from

$N u=\frac{h D_{s}}{k_{g}}=2+\frac{0.589(\mathrm{GrPr})^{1 / 4}}{\left[1+(0.469 / \mathrm{Pr})^{9 / 16}\right]^{4 / 9}}$

which decreases to be 2 when $G r$ number is nearly zero under a micro-gravity condition.

In addition the loss term in Eq. (3) is defined as:

$q_{\text {Loss }}=\frac{\dot{q}_{\text {cond. }}^{\prime \prime}+\sigma\left(T_{s}^{4}-T_{\infty}^{4}\right)}{\dot{m}^{\prime \prime}}$

The heat loss term in Eq. (3d) includes that conducted into the particle and especially the re-radiation losses from the surface, which are very important for large solid particles ( $>5 \mathrm{~mm}$ here) compared to the small droplets (less than $1 \mathrm{~mm}$ ) usually investigated in the literature [1-11].

Based on Eqs. (3a)-(3d) and supported by the experimental observations we can make the following comments:

1. The mass pyrolysis rates will decrease more rapidly in larger particles from normal to microgravity conditions for two reasons: (a) the Nusselt time will decrease more (for example by a factor of two as calculations can show) and (b) the loss term in Eq. (3d) will increase more, possibly even leading in some cases to extinction of the burning if the mass flux becomes less than a critical value $[17,18,25]$. These conclusions are supported by the variation of luminance in Fig. 5 and the burning rate in Fig 8 represented by the history of projected particle area, based on $\mathrm{d}^{2}$-law, in accordance with Eq. (3) (assuming constant Nusselt and $B$ number).

2. It takes less time for the gaseous flame shape to adjust to the microgravity conditions compared to the burning rate and luminance as Fig. 6 shows, the reason being that the diffusion times in the gas phase are much smaller than the diffusion times in the solid pyrolysis. Another fact is that the luminance depends on temperature and concentration of soot. Soot particles, although maybe a very small amount, are trapped inside the diffusion flame by thermophoretic force in microgravity. This could also somehow lead to that the luminance decreased slower than the flame height.

3. Further verification of these observations is provided in the next section where the luminance measured by the CCD camera is used to deduce line in sight average temperatures. Note that the flame temperature [[21] Eqs. (10)-(69)] is expected to decrease under microgravity condition, the heat losses term (Eq. (3d)) becomes more significant as the burning rate decreases.

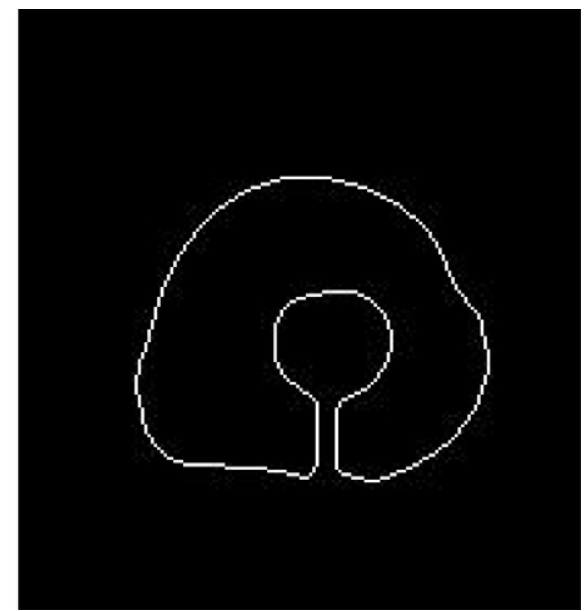

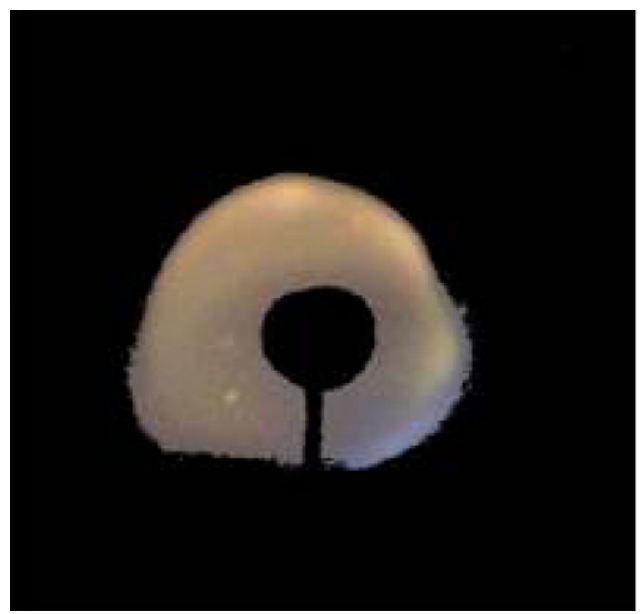

Fig. 7. Edge determination of the burning sample based on edge detection method by Canny [20]. 


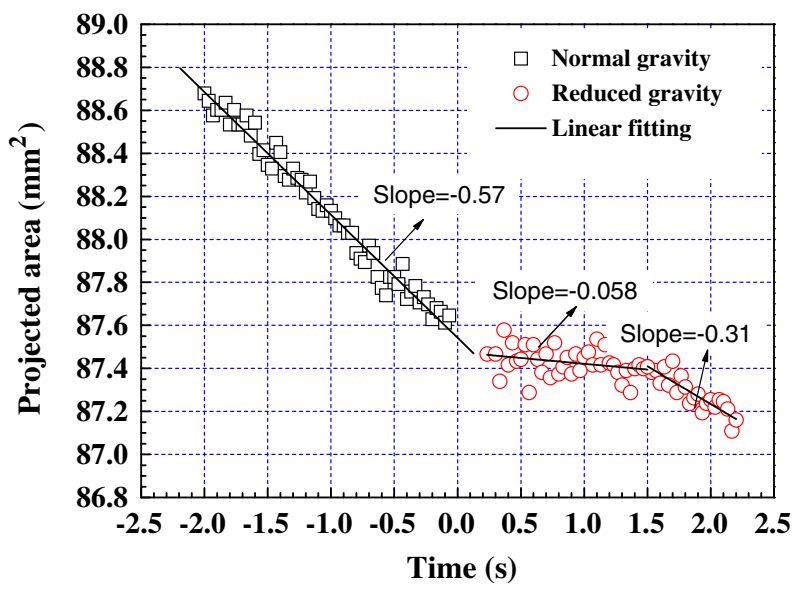

(a) Linear correlation of average projected area with time

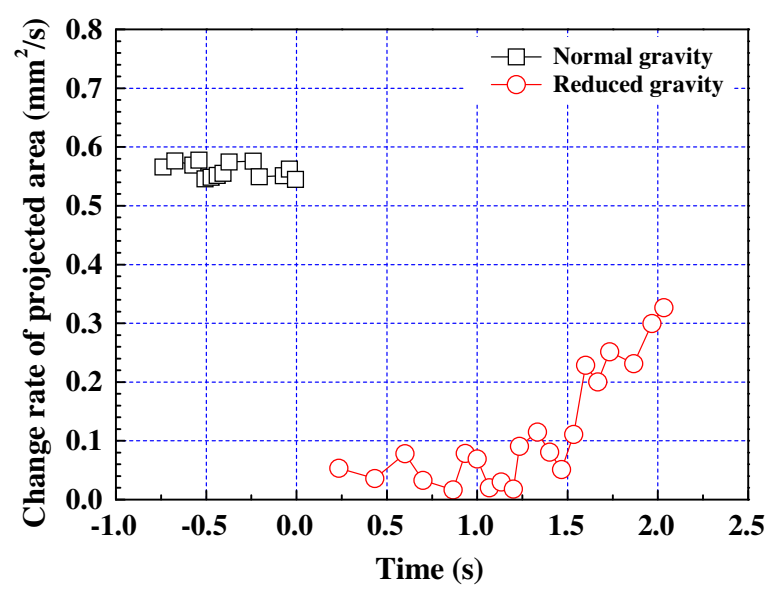

(b) Rate of change of projected area with time

Fig. 8. Variation of burning rate based on projected area for a $10 \mathrm{~mm}$ particle.

\subsection{Apparent temperature evolution and distribution}

This section describes the determination of an apparent temperature field based on line of emission measurements using the CCD camera that also determines the total luminance. The on line emission intensity was filtered at three wave lengths two of which exhibited saturation limits as demonstrated in the following discussion. Consequently only the blue one could be used calibrated by a thermocouple as described next. It was also assumed that the emissivity depends only on temperature with a spatially uniform very small soot concentration, as the flame produced by the fuel is with little soot. The results provide an on line average temperature distribution, to indicate qualitatively the 2-D spatially relative difference of temperature, as well as that of radiation energy intensity, within the flame and its evolution with gravity condition.

The black body radiation energy, $E$, of an object with temperature of $T$ can be estimated by Planck Law,

$$
\begin{aligned}
& I_{\lambda, b}(\lambda, T)=\varepsilon(\lambda, T) \frac{2 h c_{0}^{2}}{\lambda^{5}\left[\exp \left(\frac{h c_{0}}{\lambda k T}\right)-1\right]} \\
& E_{\lambda, b}(\lambda, T)=\pi I_{\lambda, b}(\lambda, T)=\varepsilon(\lambda, T) \frac{C_{1}}{\lambda^{5}\left[\exp \left(\frac{C_{2}}{\lambda T}\right)-1\right]}
\end{aligned}
$$

where $C_{1}$ and $C_{2}$ are the first and the second constant with values of
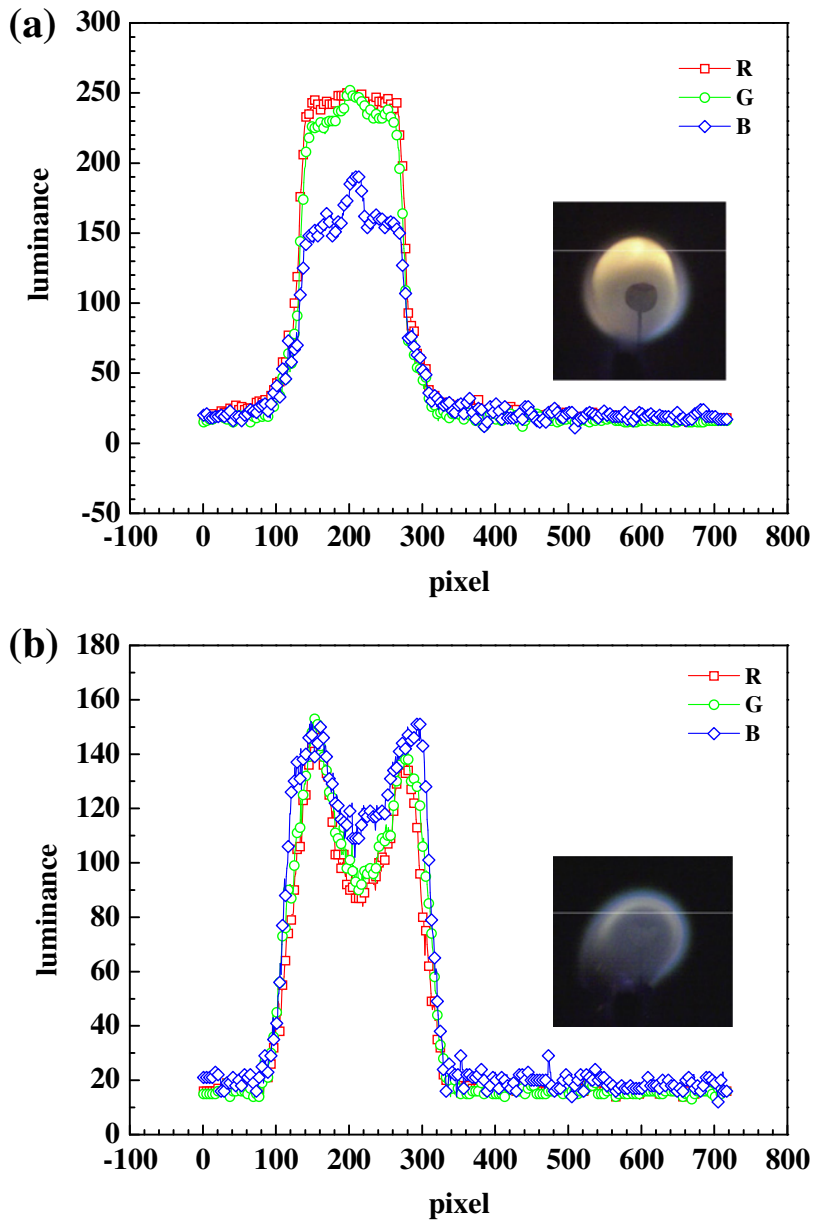

Fig. 9. Color saturation checks showing that the red and green wavelengths are saturated. (For interpretation of the references to color in this figure legend, the reader is referred to the web version of this article.)

$C_{1}=2 \pi h c_{0}^{2}=3.742 \times 10^{8} \mathrm{~W} \cdot \mu \mathrm{m}^{4} / \mathrm{m}^{2}$

$C_{2}=\frac{h c_{0}}{k}=1.439 \times 10^{4} \mu m \cdot K$

Within the visible light spectrum wavelength (390 nm-780 nm) of the flames with temperature less than $3000 \mathrm{~K}$, where $\exp \left(\frac{C_{2}}{\lambda T}\right) \succ \succ 1$, the Planck Law can be simplified and replaced by Wien Law,

$E_{\lambda, b}(\lambda, T)=\pi I_{\lambda, b}(\lambda, T)=\varepsilon(\lambda, T) \frac{C_{1}}{\lambda^{5}\left[\exp \left(\frac{C_{2}}{\lambda T}\right)\right]}$

For a given reference pixel point in the image $\left(i_{0}, j_{0}\right)$, corresponding to a temperature $T\left(i_{0}, j_{0}\right)$ the radiation energy is denoted as $M\left(i_{0}, j_{0}\right)$. For any other pixel point, the temperature is $T(i, j)$ and its radiation energy is $M(i, j)$. According to Eq. (8):

$$
\left\{\begin{array}{c}
M\left(i_{0}, j_{0}\right)=\pi I_{\lambda, b}(\lambda, T)=\varepsilon\left(\lambda, T\left(i_{0}, j_{0}\right)\right) \frac{c_{1}}{\lambda^{5} \exp \left[\frac{c_{2}}{\lambda T\left(i_{0} j_{0}\right)}\right]} \\
M(i, j)=\pi I_{\lambda, b}(\lambda, T)=\varepsilon(\lambda, T(i, j)) \frac{c_{1}\left[\frac{c_{2}}{\lambda^{5} \exp \left[\frac{c_{2}}{\lambda T(i, j)}\right]}\right.}{}
\end{array}\right.
$$

which gives

$\frac{M\left(i_{0}, j_{0}\right)}{M(i, j)}=\frac{\varepsilon\left(\lambda, T\left(i_{0}, j_{0}\right)\right)}{\varepsilon(\lambda, T(i, j))} \exp \left[\frac{C_{2}}{\lambda T(i, j)}-\frac{C_{2}}{\lambda T\left(i_{0}, j_{0}\right)}\right]$ 
and

$\ln \frac{M\left(i_{0}, j_{0}\right)}{M(i, j)}=\ln \frac{\varepsilon\left(\lambda, T\left(i_{0}, j_{0}\right)\right)}{\varepsilon(\lambda, T(i, j))}+\frac{C_{2}}{\lambda T(i, j)}-\frac{C_{2}}{\lambda T\left(i_{0}, j_{0}\right)}$

Rearranging Eq. (11), gives

$$
T(i, j)=\frac{C_{2}}{\lambda\left[\ln \frac{M\left(i_{0}, j_{0}\right)}{M(i, j)}-\ln \frac{\varepsilon\left(\lambda, T\left(i_{0}, j_{0}\right)\right)}{\varepsilon(\lambda, T(i, j))}+\frac{C_{2}}{\lambda T\left(i_{0}, j_{0}\right)}\right]}
$$

For a certain wavelength $\lambda$, the term, $\ln \frac{\varepsilon\left(\lambda, T\left(i_{0}, j_{0}\right)\right)}{\varepsilon(\lambda, T(i, j))}$, can be approximated by Taylor expansion, assuming that the emissivity is independent of local soot concentration, or the soot distribution is uniformly small for such a fuel.

$\ln \frac{\varepsilon\left(\lambda, T\left(i_{0}, j_{0}\right)\right)}{\varepsilon(\lambda, T(i, j))}=a_{0}+a_{1}\left(T(i, j)-T\left(i_{0}, j_{0}\right)\right)+\cdots$
So, the temperature can be calculated by

$$
T(i, j)=\frac{C_{2}}{\lambda\left[\ln \frac{M\left(i_{0}, j_{0}\right)}{M(i, j)}-\left(a_{0}+a_{1}\left(T(i, j)-T\left(i_{0}, j_{0}\right)\right)+\frac{C_{2}}{\lambda T\left(i_{0} j_{0}\right)}\right]\right.}
$$

The values of the constant $a_{0}$ and $a_{1}$ were calibrated by measurement of two $0.5 \mathrm{~mm}$ diameter thermocouples under normal-gravity condition, which were positioned within the flame, being $2 \mathrm{~mm}$ and $5 \mathrm{~mm}$ above the fuel ball, where the temperature measured was $977^{\circ} \mathrm{C}$ and $1047^{\circ} \mathrm{C}$, respectively. The effective wavelength for the three colors, R, G, B, is taken as $700 \mathrm{~nm}, 546.1 \mathrm{~nm}$ and $435.8 \mathrm{~nm}$, respectively. The one $5 \mathrm{~mm}$ above the fuel ball is selected as the reference temperature. The temperature deduced by monochromatic method is $940^{\circ} \mathrm{C}$, which is near the value measured by thermocouple. For such a monochromatic CCD temperature-measurement

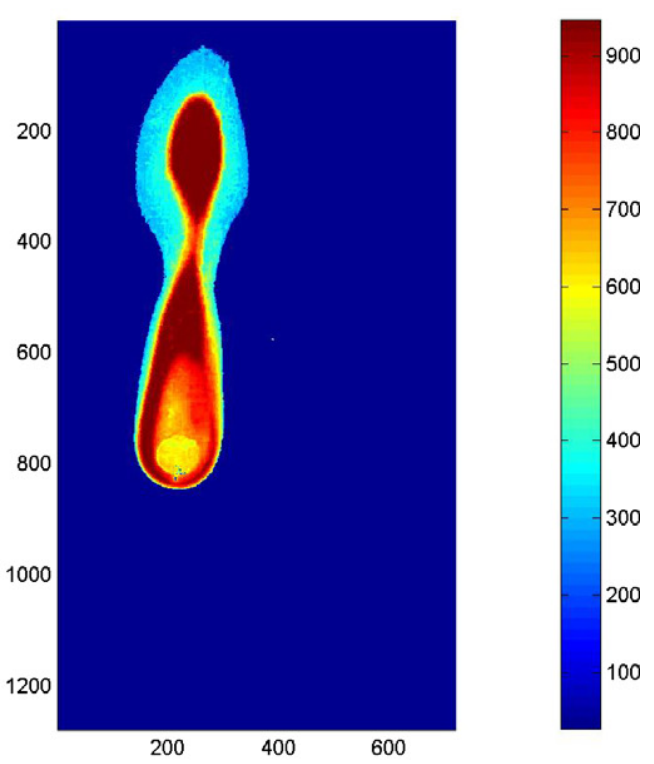

(a) normal-gravity

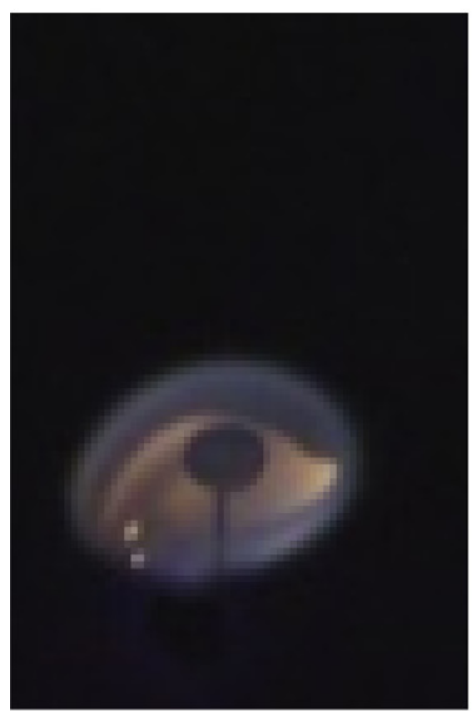

(b) reduced-gravity

Fig. 10. Flame temperature measured by the monochromatic CCD temperature-measurement method under normal- and reduced-gravity conditions. 
method, the saturation of the image processing should be taken into account. The processing of the typical image based on the Red, Green and Blue color is shown in Fig. 9. The processing based on the color of Red and Green seems to saturate, but Blue not. So, only the Blue color is selected for image processing.

Fig. 10 compares the 2-D temperature distribution deduced from the flame ball images under normal- and reduced-gravity condition. It is shown that under normal gravity condition, the highest temperature appears at a certain distance above the fuel. However, under a reduced-gravity condition, the flame temperature seemed to distribute much more evenly around the fuel. Besides, the average temperature of the flame ball is obviously lower under a reduced-gravity condition than that under a normal-gravity condition.
Fig. 11 presents the time history of the 2-D apparent temperature distribution within the flame during the transition from normal- to reduced-gravity condition, deduced from the image series shown in Fig. 4(b). There are some small points distributed occasionally within the field. This should be due to some small amount of soot with relative high emissivity. However, this does not affect the indication of these series for an overall qualitative relative distribution of temperature and the variation trend of overall temperature with gravity level. From this series, it is shown that when the flame suddenly goes into a reduced-gravity condition, the relative high temperature contour (white region as shown) gradually moves towards the fuel particle surface (frames 6-16) followed by a decrease of apparent temperature as the flame again wraps around the particle (20-46), until near the end of the

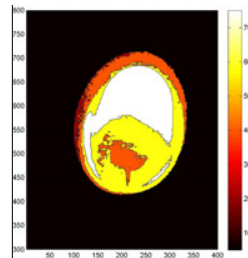

6

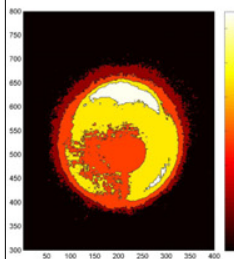

18

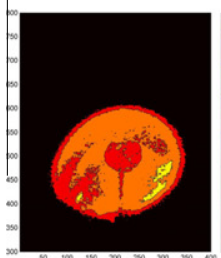

30

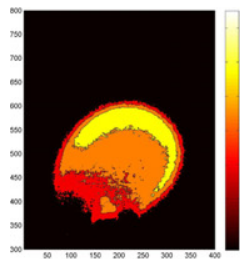

42

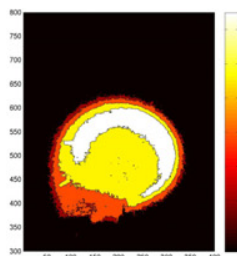

52

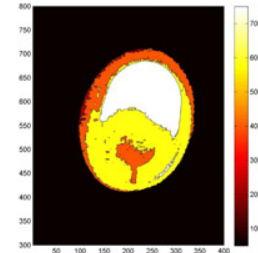

8

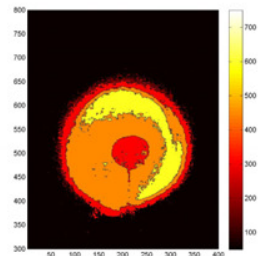

20

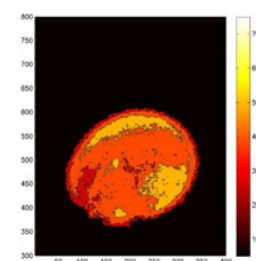

32

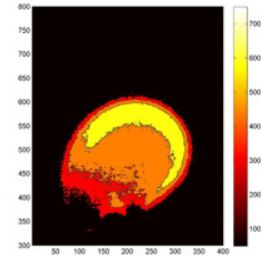

44

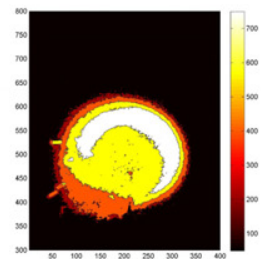

54

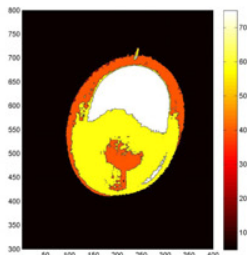

10

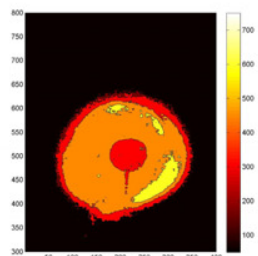

22

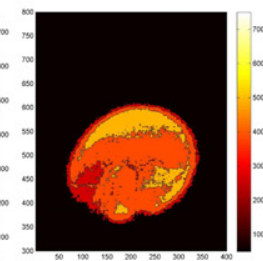

34

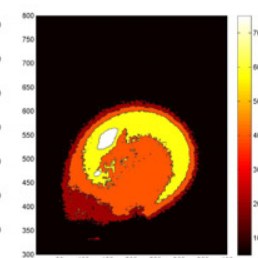

46

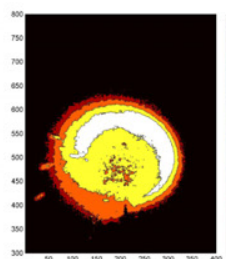

56

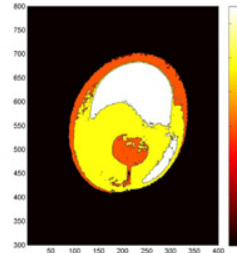

12

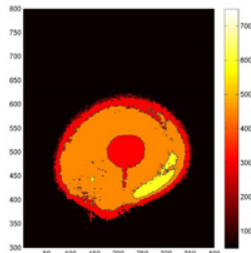

24

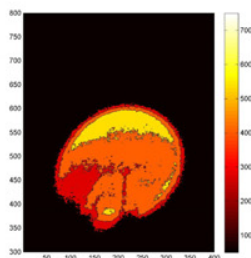

36

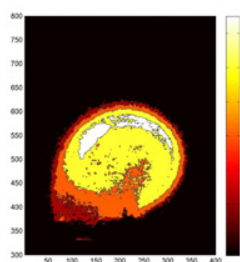

47

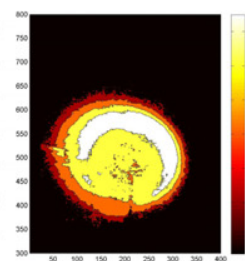

58

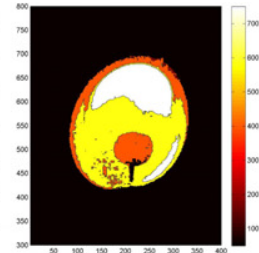

14

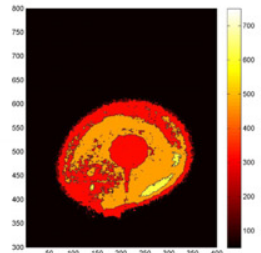

26

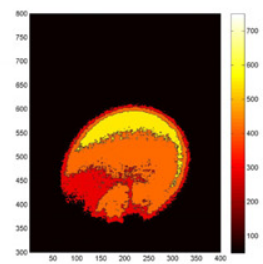

38

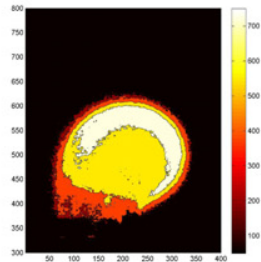

48

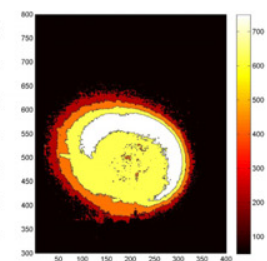

60

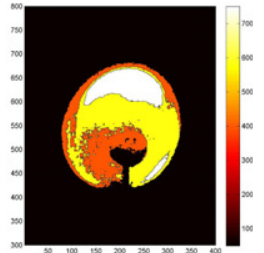

16

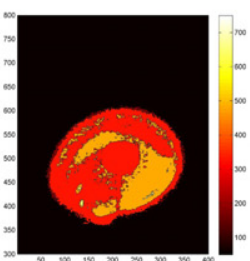

28

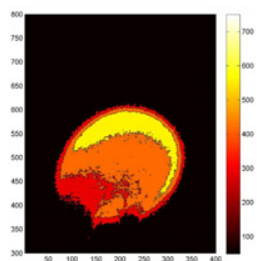

40

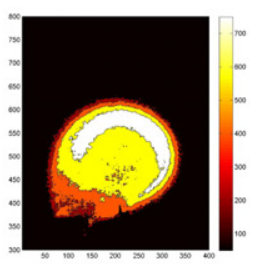

50

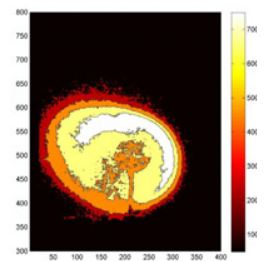

62

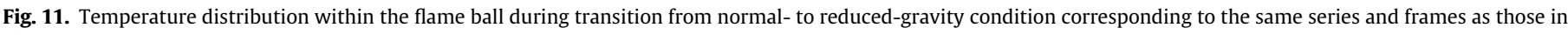
Fig. 4. 
drop where the flame starts again moving upwards from the particle with high temperature contour also showing again at the outer flame surface.

\section{Concluding remarks}

Experiments were carried out in a simplified drop facility for investigating the development of the flame shape, luminance, burning rate and relative apparent temperature distribution for the transition from normal to reduced-gravity conditions for a special solid fuel which does not melt but sublimates directly to flammable $\mathrm{CH}_{4}$ and $\mathrm{H}_{2}$ producing a diffusive sootless flame. These combustion characteristics during such a transition has been explained by using combustion theory for the burning of a solid particle accounting carefully for surface radiation losses (see Eqs. (3a)-(3d)).

The main conclusions are:

1. The change of the flame shape is much faster than that of the luminance, indicating as expected that the evolution of the gas flow dynamics is much faster than that of the heat balance and combustion intensity.

2. The luminance of the flame is found to decrease to a lower level during most of the drop but followed by a small increment near the end of the drop owing to a slight increase of gravitational acceleration near the end of the drop.

3. The change of the burning of the larger particles is theoretically analyzed to be greater and occur faster than the change of the burning of the smaller particles. This is owing to the larger drop of the burning rate for large particles which is related to the decrease of the heat transfer coefficient (Nusselt number) and the increasing importance of the radiation losses from the surface. The flame temperatures in reduced gravity are lower because the radiation losses are more significant in reduced gravity as the mass burning rate decreases. Such transitional effect, as also evidenced by change of luminance, is less pronounced for a smaller fuel particle than for a larger one.

4. The present results allow us to conclude that change from normal to microgravity conditions will reduce possible fire hazards whereas change in the opposite direction will increase possible fire hazards in space travel during the combustion of a solid non dripping particle.

\section{Acknowledgements}

This work is supported by Natural Science Foundation of China (NSFC) under Grant No. 51176180, Fundamental Research Funds for the Central Universities, Program for New Century Excellent Talents in University under Grant No. NCET-09-0914 and Key Laboratory of Microgravity, Institute of Mechanics, Chinese Academy of Sciences. Prof. Michael Delichatsios was supported to be involved into this work by Chinese Academy of Science Visiting Professorship for Senior International Scientists under Grant No. 2009Z2-30.

\section{References}

[1] C.H. Wang, G.J. Ueng, An experimental investigation of fuel droplet combustion under micro-gravity, Int. Comm. Heat Mass Transfer 24 (7) (1997) 931-944.

[2] K. Okai, M. Tsue, M. Kono, J. Sato, D.L. Dietrich, F.A. Williams, An experimental study of microgravity combustion of a droplet near a wall, Combust. Flame 133 (2003) 169-172.

[3] J.R. Yang, S.C. Wong, On the discrepancies between theoretical and experimental results for microgravity droplet evaporation, Int. J. Heat Mass Transfer 44 (2001) 4433-4443.

[4] Y. Jin, B.D. Shaw, Computational modeling of n-heptane droplet combustion in air-diluent environments under reduced-gravity, Int. J. Heat Mass Transfer 53 (2010) 5782-5791.

[5] V. Dee, B.D. Shaw, Combustion of propanol-glycerol mixture droplets in reduced gravity, Int. J. Heat Mass Transfer 47 (2004) 4857-4867.

[6] S.L. Manzello, M.Y. Choi, A. Kazakov, F.L. Dryer, R. Dobashi, T. Hirano, The burning of large n-heptane droplets in microgravity, Proc. Combust. Inst 28 (2000) 1079-1086.

[7] S.L. Manzello, A. Yozgatligil, M.Y. Choi, An experimental investigation of sootshell formation in microgravity droplet combustion, Int. J. Heat Mass Transfer 47 (2004) 5381-5385.

[8] A. Yozgatligil, Seul-hyun Park, M.Y. Choi, Burning and sooting behavior of ethanol droplet combustion under microgravity conditions, Combust. Sci. Tech 176 (2004) 1985-1999.

[9] M. Mikami, H. Oyagi, N. Kojima, M. Kikuchi, Y. Wakashima, S. Yoda, Microgravity experiments on flame spread along fuel-droplet arrays using a new droplet-generation technique, Combust. Flame 141 (2005) 241-252.

[10] Y. Ogami, S. Sakurai, S. Hasegawa, M. Jangi, H. Nakamura, K. Yoshinaga, H. Kobayashi, Microgravity experiments of single droplet combustion in oscillatory flow at elevated pressure, Proc. Combust. Inst 32 (2009) 21712178.

[11] F. Takahashi, G.T. Linteris, V.R. Katta, Extinguishment of methane diffusion flames by carbon dioxide in coflow air and oxygen-enriched microgravity environments, Combust. Flame 155 (2008) 37-53.

[12] S.D. Tse, D.L. Zhu, C.J. Sung, Y.G. Ju, C.K. Law, Microgravity burner-generated spherical diffusion flames: experiment and computation, Combust. Flame 125 (2001) 1265-1278.

[13] S.F. Wang, H. Zhang, J. Jarosinski, A. Gorczakowski, J. Podfilipski, Laminar burning velocity and Markstein Lengths of premixed methane/air flames near the lean flammability limit in microgravity, Combust. Flame 157 (2010) 667675.

[14] J.C. Yang, A. Hamins, M.K. Donnelly, Reduced gravity combustion of thermoplastic spheres, Combust. Flame 120 (2000) 61-74.

[15] E.L. Dreizin, Experimental study of aluminum particle flame evolution in normal and micro-gravity, Combust. Flame 116 (1999) 323-333.

[16] Y. Nakamura, T. Kashiwagi, S.L. Olson, K. Nishizawa, O. Fujita, K. Ito, Two-sided ignition of a thin PMMA sheet in microgravity, Proc. Combust. Inst 30 (2005) 2319-2325.

[17] S. Bhattacharjee, K. Wakai, S. Takahashi, Predictions of a critical fuel thickness for flame extinction in a quiescent microgravity environment, Combust. Flame 132 (2003) 523-532.

[18] R.A. Altenkirch, L. Tang, K. Sacksteder, S. Bhattacharjee, M.A. Delichatsios, Inherently unsteady flame spread to extinction over thick fuels in microgravity, Proc. Combust. Inst 25 (1998) 2515-2524.

[19] J.B. Armstrong, S.L. Olson, J.S. T'ien, Transient model and experimental validation of low-stretch solid-fuel flame extinction and stabilization in response to a step change in gravity, Combust. Flame 147 (2006) 262-277.

[20] J. Canny, A computational approach to edge detection, IEEE Trans. Pattern Anal. Mach. Intell. PAMI-8 (6) (1986) 679-698.

[21] S. Turns, An Introduction to Combustion: Concepts and Applications, second ed., Mc-Graw Hill, 2000. pg.374.

[22] S. Dembele, J.X. Wen, Investigation of a spectral formulation for radiative heat transfer in one-dimensional fires and combustion systems, Int. J. Heat Mass Transfer 43 (2000) 4019-4030.

[23] W.F. Du, W.R. Hu, Effect of ambient pressure and radiation reabsorption of atmosphere on the flame spreading over thermally thin combustibles in microgravity, Sci. China Ser. E Technol. Sci 46 (2003) 405-412.

[24] J. Jiang, Y. Hao, Y.X. Tao, Experimental investigation of convective melting of granular packed bed under microgravity, ASME Trans. J. Heat Transfer 124 (2002) 516-524.

[25] M.A. Delichatsios, Surface extinction of flames on solids: some interesting results, Proc. Combust. Inst 31 (2007) 2749-2756. 